\title{
Theory for incongruent crystallization: application to a ZBLAN glass
}

\author{
G. DE LEEDE*, R. BEERKENS, E. VAN DUIN, H. DE WAAL \\ TNO Institute of Applied Physics, Delft, The Netherlands
}

Equations which describe incongruent nucleation and subsequent crystal growth have been derived. $\mathrm{A} \mathrm{ZrF}_{4}-\mathrm{BaF}_{2}-\mathrm{LaF}_{3}-\mathrm{AlF}_{3}-\mathrm{NaF}$ glass was used to test the validity of these equations. Nucleation rate measurements were fitted to theory and some growth rate measurements were found in reasonable agreement with theoretical predictions. Both nucleation theory and crystal growth theory were used for computer simulations of the crystallization behaviour during heat treatments. Some heat treatments were performed in a differential scanning calorimeter to verify the theories. The experimental results were in good agreement with the numerical data. Using these theoretical results it is possible to estimate fibre scattering losses due to crystallization. Depending on drawing temperature, estimated losses can vary from 0.014 $\left(310^{\circ} \mathrm{C}\right)$ to $25\left(320^{\circ} \mathrm{C}\right)$ or more $\mathrm{dB} \mathrm{km}^{-1}$.

\section{Nomenclature}

$a_{\mathrm{s}} \quad$ the chemical activity of component $\mathrm{A}$ in solution referred to the activity of the component in crystalline form

$c_{\mathrm{c}}^{\mathrm{A}} \quad$ the concentration of $\mathrm{A}$ in the crystalline form $\left(\mathrm{mol} \mathrm{m}{ }^{-3}\right)$

$c_{\mathrm{r}}^{\mathrm{A}} \quad$ the concentration of $\mathrm{A}$ in the liquid at the interface $\left(\mathrm{mol} \mathrm{m}^{-3}\right)$

$c_{1}^{\mathbf{A}}$ the concentration of $\mathrm{A}$ far from the interface in the bulk (mol $\mathrm{m}^{-3}$ )

$c_{\mathrm{e}}^{\mathrm{A}}$ the equilibrium concentration of $\mathrm{A}\left(\mathrm{mol} \mathrm{m}^{-3}\right)$

$D$ the diffusion coefficient $\left(\mathrm{m}^{2} \mathrm{~s}^{-1}\right)$

$\delta G$ the free energy difference between the liquid and the crystal, equal to the molar Gibbs' free enthalpy of component $A$ in solution minus the molar Gibbs' enthalpy of the crystalline form of $\mathrm{A}\left(\mathrm{J} \mathrm{mol}^{-1}\right)$.

$-\Delta G$ free energy difference between crystal $A$ and pure liquid $\mathrm{A}\left(\mathrm{J} \mathrm{mol}^{-1}\right)$

$\Delta G_{\mathrm{a}}$ activation energy for growth $\left(\mathrm{J} \mathrm{mol}^{-1}\right)$

$\Delta G_{\mathrm{r}}$ free energy difference between the liquid (of composition $c_{r}^{\mathbf{A}}$ ) at the interface and the pure liquid $\mathrm{A}$

$\Delta G_{1}$ free energy difference between the liquid (of composition $c_{1}^{A}$ ) far from the interface and the pure liquid $\mathrm{A}$

$\Delta H_{\mathrm{f}}$ heat of fusion of the pure component $\mathrm{A}$ $\left(\mathrm{J} \mathrm{mol}^{-1}\right)$

\section{Introduction}

Although incongruent crystallization in multi-component glasses is the most common type of crystallization in practice, it is much less well studied than congruent crystallization $[1,2]$. A general model for
$I$ the nucleation frequency $\left(1 \mathrm{~m}^{-3} \mathrm{~s}^{-1}\right)$

k Boltzmann constant $\left(\mathrm{JK}^{-1}\right)$

$K$ a constant of the order $10^{32}-10^{33} \mathrm{~Pa} \mathrm{~m}^{-3} \mathrm{~K}^{-1}$

$\mathrm{r}$ the radius of the spherical crystal

$R \quad$ gas constant $\left(\mathrm{J} \mathrm{mol}^{-1} \mathrm{~K}^{-1}\right)$

$t \quad$ time (s)

$T \quad$ temperature $(\mathrm{K})$

$\Delta T \quad T_{1}-T$ the undercooling of the melt of composition $x^{\mathrm{A}}\left(T_{1}\right.$ is the liquidus of the melt and depends on $x^{\mathbf{A}}$ )

$T_{1} \quad$ liquidus temperature $(\mathrm{K})$

$T_{\mathrm{m}} \quad$ melting temperature of pure component $\mathrm{A}(\mathrm{K})$

$T_{\mathrm{p}} \quad$ temperature at the top of the DSC peak $(\mathrm{K})$

$u \quad$ crystal growth rate $\left(\mathrm{m} \mathrm{s}^{-1}\right)$

$V_{\mathrm{m}}$ molar volume of the crystallizing phase $\left(\mathrm{mol} \mathrm{m}^{-3}\right)$

$x^{\mathrm{A}} \quad$ molar fraction of the precipitating component $A$ in the melt (for an example: see Appendix)

$\eta \quad$ viscosity (Pa $\mathrm{s}$ )

$\lambda \quad$ jump distance of the order of molecular dimensions $(\mathrm{m})$

$v_{0} \quad$ frequency of vibration $\left(\mathrm{s}^{-1}\right)$

$\sigma \quad$ surface tension of the crystal-liquid interface $\left(\mathrm{J} \mathrm{m}^{-2}\right)$

$\delta \quad$ the thickness of the diffusion layer

\footnotetext{
* Present address: Philips Technology Centre for Glass, Eindhoven, The Netherlands.
} 
with diffusion-controlled growth in multi-component glasses. Here, a model is proposed that describes crystal growth in multicomponent glasses for the general case. It takes into account both the diffusion limitations to crystal growth as well as the kinetics of the transformation at the crystal-liquid interface.

As an initial test, the model has been used to describe the crystallization behaviour of a multicomponent fluorozirconate (ZBLAN) glass, which is an important candidate material for the production of ultra-low-loss fibres [4]. The predictions of the model are compared with the results of an experimental study on the crystallization of this glass. In this way, a more complete picture of the crystallization behaviour is obtained, which is used to discuss the feasibility of a low-loss fibre.

\section{Theory}

\subsection{Nucleation}

An equation which describes the nucleation rate as a function of temperature for incongruent crystallization was given in a previous paper [3]. It is based on classical nucleation theory, but with a correction for the thermodynamic driving force for crystallization, $\delta G$, because the nucleating phase has a different composition from the parent glass. The theoretical equations given there are

$$
I=\frac{K T}{\eta} \exp -\left(\frac{16 \pi \sigma^{3} V_{\mathrm{m}}^{2}}{3 k \delta G^{2} T}\right)
$$

and

$$
\begin{aligned}
\delta G & =R T \ln a_{\mathrm{s}}(T) \\
& =\Delta T\left(\Delta H_{\mathrm{f}} / T_{\mathrm{m}}-R \ln x^{\mathrm{A}}\right)
\end{aligned}
$$

Equation 2 not only contains the effect of the liquidus temperature, but also of the concentration of the crystallizing component in the solution, and the melting temperature of the component itself. If $x^{\mathrm{A}}=1$, then Equation 2 is equivalent to the approximate expression which is often used to calculate free energy differences for liquids that crystallize without a change in composition.

Equation 2 has been derived for a "regular" solution $[5,6]$ and is only approximate when the solution is not regular. A regular solution is defined by Hildebrand as

$$
R T \ln [\gamma(T)]=R T_{1} \ln \left[\gamma\left(T_{1}\right)\right]
$$

where $\gamma$ denotes the activity coefficient of the crystallizing component in the liquid phase. The use of this approximation resulted in the appearance of the liquidus temperature, $T_{1}$, in Equation 2. The net effect of a change in $x^{\mathrm{A}}$ on $\delta G$ depends also on $\Delta T=T_{1}-T$, because $T_{1}$ depends also on $x^{\mathrm{A}}$. In other words, for a regular solution it is found that the net effect of a change in $x^{A}$ on $\delta G$ depends also on the solidification curve $T_{1}\left(x^{\mathrm{A}}\right)$.

\subsection{Growth}

For systems that crystallize with a sizeable change in composition, growth is likely to be diffusion-controlled. However, the exact nature of the growth process depends also on the transformation rate at the crystal-liquid interface. The situation at the interface is depicted schematically in Fig. 1.

To the authors' knowledge, an equation describing the growth for systems which crystallize with a sizeable change in composition, for the case when the process is not diffusion controlled, is not available from the literature. We will propose such an equation here. The derivation of the growth equation follows the derivation found in many references for growth in systems where the crystallizing phase has the same composition as the liquid phase. Here an adaption is made because the crystallizing phase differs from the melt composition.

The frequency of jumping of molecules from the liquid to the crystal phase $\left(v_{1-c}\right)$ is given by

$$
v_{1-\mathrm{c}}=v_{0} \exp \left(-\Delta G_{\mathrm{a}} / R T\right) \exp \left(\Delta G_{\mathrm{r}} / R T\right)
$$

where $v_{0}$ is the vibration frequency of the molecule. The frequency of jumping from crystal to liquid $\left(v_{\mathrm{c}-1}\right)$ is

$$
v_{\mathrm{c}-1}=v_{0} \exp \left(-\Delta G_{\mathrm{a}} / R T\right) \exp (\Delta G / R T)
$$

The velocity of crystal growth is the net jump rate times $\lambda$, the distance between liquid and crystal (increment of the crystal size per jump)

$$
\begin{array}{r}
u=\lambda_{0} v \exp \left(-\Delta G_{\mathrm{a}} / R T\right) \\
{\left[\exp \left(\Delta G_{\mathrm{r}} / R T\right)-\exp (\Delta G / R T)\right]}
\end{array}
$$

Note that (i) at $T=T_{1}, \Delta G_{\mathrm{r}}=\Delta G$ and thus $u=0$, (ii) when $x_{\mathrm{r}}^{\mathrm{A}}=1$ (congruent crystallization) $\Delta G_{\mathrm{r}}=0$ : this leads to the well-known equation describing congruent crystallization.

The flux of molecules, $j$, arriving at the interface should equal the flux of molecules that attach them-
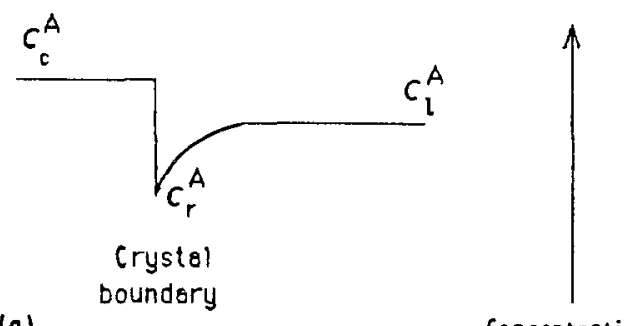

Concentration

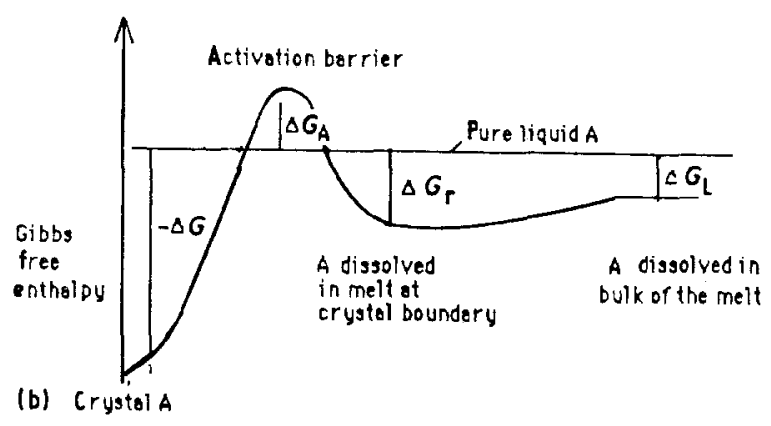

Figure 1 (a) Concentration profile at the crystal-liquid interface and (b) the energy differences for crystallization. 
selves to the growing crystal

$$
j=u\left(c_{\mathrm{c}}^{\mathrm{A}}-c_{\mathrm{r}}^{\mathrm{A}}\right)
$$

$u c_{r}^{A}$ is added to correct for solute rejection, due to the interface which moves with velocity $u$ through a liquid of composition $c_{\mathrm{r}}^{\mathrm{A}}$.

The flux of molecules arriving at the interface is determined by diffusion from the bulk liquid towards the crystal surface. It is approximated via the diffusion coefficient

$$
j=(D / \delta)\left(c_{1}^{\mathrm{A}}-c_{\mathrm{r}}^{\mathrm{A}}\right)
$$

For the quasi-stationary state diffusion, the following relation is found [7]:

$$
1 / \delta=\left[1 / r+1 /(\pi \mathrm{D} t)^{1 / 2}\right]
$$

With Equations 6-8 we now have a general set of equations which give the growth kinetics of incongruent crystallisation. Equation 9 can be used for the estimation of the diffusion layer thickness. For the calculation we need to determine the free energy differences $\Delta G_{\mathrm{r}}$ and $\Delta G$. An approximate expression for $\Delta G_{\mathrm{r}}$ is derived in the literature [8], assuming the melt to be a regular solution

$$
\begin{aligned}
\Delta G_{\mathrm{r}}= & \Delta H_{\mathrm{f}}\left(T_{\mathrm{l}}-T_{\mathrm{m}}\right) / T_{\mathrm{m}} \\
& +R T\left(1-T_{\mathrm{l}} / T\right) \ln \left(x_{\mathrm{r}}^{\mathrm{A}}\right)
\end{aligned}
$$

where $x_{r}^{\mathbf{A}}$ is the fraction of $\mathrm{A}$ at the interface. An approximate expression for $\Delta G$ may also be obtained from the literature [9]

$$
\Delta G=\Delta H_{\mathrm{f}}\left(T_{\mathrm{m}}-T\right) / T_{\mathrm{m}}
$$

The activation energy for crystal growth, $\Delta G_{\mathrm{a}}$, can be evaluated by relating it to the diffusion coefficient, which in turn can be related to the viscosity by means of the Stokes-Einstein equation. This is a common procedure which has been described elsewhere [1].

Equations 6-11 form a complete set of equations for the description of incongruent crystallization. Two limiting cases can be distinguished.

1. If the transformation rate at the interface is slow compared to the diffusion process, then $c_{\mathrm{r}}^{\mathbf{A}} \gg c_{\mathrm{e}}^{\mathbf{A}}$ $\left(c_{\mathrm{r}}^{\mathrm{A}} \approx c_{1}^{\mathrm{A}}\right.$ for a very low transformation rate) and the process will be controlled by interface kinetics. In this case, $\Delta G_{\mathrm{r}}=\Delta G_{1}$ in Equation 6 .

2. If the transformation rate at the interface is rapid compared to the diffusion process, then $c_{\mathrm{r}}^{\mathrm{A}} \approx c_{\mathrm{c}}^{\mathrm{A}}$ and the process is diffusion limited. Now $\Delta G_{\mathrm{r}} \neq \Delta G_{1}$. The growth rate can be calculated by solving the diffusion equation for this case.

\subsection{Computer simulations of nucleation and growth}

The equations derived in the preceding paragraph can be used to simulate the crystallization during heat treatments of glass samples. The degree of crystallinity of a glass sample can be calculated by a numerical method described by Yinnon and Uhlmann [10]. The degree of crystallinity at a certain moment is calculated as the sum of the volumes of all the crystallites (of different sizes) present in the glass sample at that instant of time. The number of crystals and their size distribution are determined by the temperature history and the dependencies on temperature of the nucleation and the growth rates. These dependencies are given by Equations 1 and 6 . The temperature history of the fluoride glass studied here is described in more detail in the experimental section.

The computer simulations were made for the case of bulk nucleation and crystal growth only, so surface nucleation is excluded from the calculations. The effect of the surface nucleation will be treated in the discussion.

\section{Experimental procedure}

In this section we present the results of an experimental study of the crystallization behaviour of a fluorozirconate glass. The bulk nucleation rate and the growth rate of the crystals were studied by optical methods, after applying certain heat treatments to glass samples. The crystallization behaviour of the fluoride glass was also studied by differential scanning calorimetry (DSC), which is very appropriate for fluoride glasses because their crystal growth rates are relatively high, and because the crystallization temperature range is low. The DSC experiments were done by heating small samples of glass at various heating rates. As explained below, these DSC experiments were used to test the accuracy of the nucleation rate measurements and their fit to the theoretical equation, as well as the theoretical growth equation.

\subsection{Sample preparation}

The composition ( $\mathrm{mol} \%$ ) of the fluoride glass of this study was: $53 \mathrm{ZrF}_{4}, 20 \mathrm{BaF}_{2}, 4 \mathrm{LaF}_{3}, 3 \mathrm{AlF}_{3}, 20 \mathrm{NaF}$. The batches were prepared from material of $99.9 \%$ purity and $\mathrm{NH}_{4} \mathrm{~F} \cdot \mathrm{HF}$ was used for fluorination of $\mathrm{ZrO}_{2}$ (DSC experiments) and/or residual oxygen impurities. The batches were melted in a vitreous carbon crucible placed in a quartz tube with an O-ring sealed glass lid. They were treated at $400{ }^{\circ} \mathrm{C}$ for $1 \mathrm{~h}$, followed by melting at $850^{\circ} \mathrm{C}$ for $1 \mathrm{~h}$. The batch was melted in an argon $/ \mathrm{CCl}_{4}$ atmosphere.

The samples used for the DSC measurements were all taken from a glass using $\mathrm{ZrO}_{2}$ and sufficient ammonium bifluoride as starting materials. After sufficient melting, these glasses were cooled and annealed at $240^{\circ} \mathrm{C}$ for about $40 \mathrm{~min}$ before cooling to room temperature in about $4 \mathrm{~h}$. Sublimated $\mathrm{ZrF}_{4}$ was used for the preparation of glasses for the study of crystal growth rates. These glasses were annealed for only $10 \mathrm{~min}$ and slowly cooled to room temperature, to give a rod of $10 \mathrm{~mm}$ diameter and $100 \mathrm{~mm}$ length.

\subsection{DSC measurements}

Pieces of glass were crushed and sieved. Two particle sizes were used for the DSC measurements: particles with a sieve fraction from $0.16-0.25 \mathrm{~mm}$ (average 0.21 $\mathrm{mm}$ ) and from $0.63-1.00 \mathrm{~mm}$ (average $0.82 \mathrm{~mm}$ ). $10-20 \mathrm{mg}$ samples of glass were scanned in the differential scanning calorimeter (Perkin-Elmer DSC7 with 
TAC $7 / 3$ controller) with a constant heating rate from $200^{\circ} \mathrm{C}$ up to the melting temperature. The heating rates were varied from $2.5-50 \mathrm{~K} \mathrm{~min}^{-1}$. In all cases an exothermic crystallization peak was found, and the temperature, $T_{\mathrm{p}}$, at which the transformation rate was maximum (displayed by the extremum of the DSC peak) was determined.

\subsection{Growth rate measurements}

Small fractions of three glass rods were cut, polished and etched in $\mathrm{ZrOCl}_{2} \cdot 8 \mathrm{H}_{2} \mathrm{O}$ in $1 \mathrm{~N} \mathrm{HCl}$ solution [11]. This solution was used for treatment of the surface because it was found that the condition of the surface influences the crystal layer thickness for a fluoride glass which is reheated [12]. Etching the glasses was found to give reproducible results.

The glass pieces were then heat-treated at various temperatures for various times. For Rod 1, the temperatures were 310 and $320^{\circ} \mathrm{C}$, pieces of Rod 2 were treated at 330,340 and $350^{\circ} \mathrm{C}$, whereas pieces of Rod 3 were used for 360 and $374^{\circ} \mathrm{C}$ (it was found during the study that the results were reproducible when using pieces of the same rod, but the reproducibility was worse for pieces taken from different rods).

A tubular furnace with parabolic temperature profile was used for heating, and variations in temperature were kept smaller than $1{ }^{\circ} \mathrm{C}$. The specimens were placed in a $10 \mathrm{~mm}$ diameter brass cup with a $\mathrm{Pt} / \mathrm{Rh}$ thermocouple underneath. They were quickly shifted into the tube furnace to a region where the temperature was found to reach the desired value. In this way, the period of heating up the specimen was kept as short as possible, thus reducing the inaccuracy of the calculated growth rates. The atmosphere in the furnace could be flushed with dry nitrogen and the exit flow was monitored for $\mathrm{H}_{2} \mathrm{O}$ content with an $\mathrm{Al}_{2} \mathrm{O}_{3}$ sensor.

After heat treatment at temperatures between 300 and $370^{\circ} \mathrm{C}$, the glasses were quickly cooled to $T_{\mathrm{g}}$ and annealed for about $30 \mathrm{~min}$ before cooling to room temperature. The time-temperature histories in heating and cooling of all samples were kept equal as much as possible. Several samples of the same rod were used to determine the growth rate at one temperature. An optical microscope was used to measure the thickness of the crystalline layer. Because the layer which had made contact with the bottom of the sample holder was almost always larger than the one at the top of the specimen, the free surface was used for measurements of layer thickness. Average values of at least ten measurements of layer thickness were used because individual values could vary by more than $30 \%$ depending on the condition of the surface and the atmosphere.

After crystallization, some samples were investigated by X-ray diffraction (XRD).

\section{Results}

\subsection{DSC measurements}

The results of the DSC measurements are depicted in Fig. 2, which gives the temperatures, $T_{p}$, at the maximum of the DSC peak as a function of heating rate, for two different particle sizes. It is obvious that an

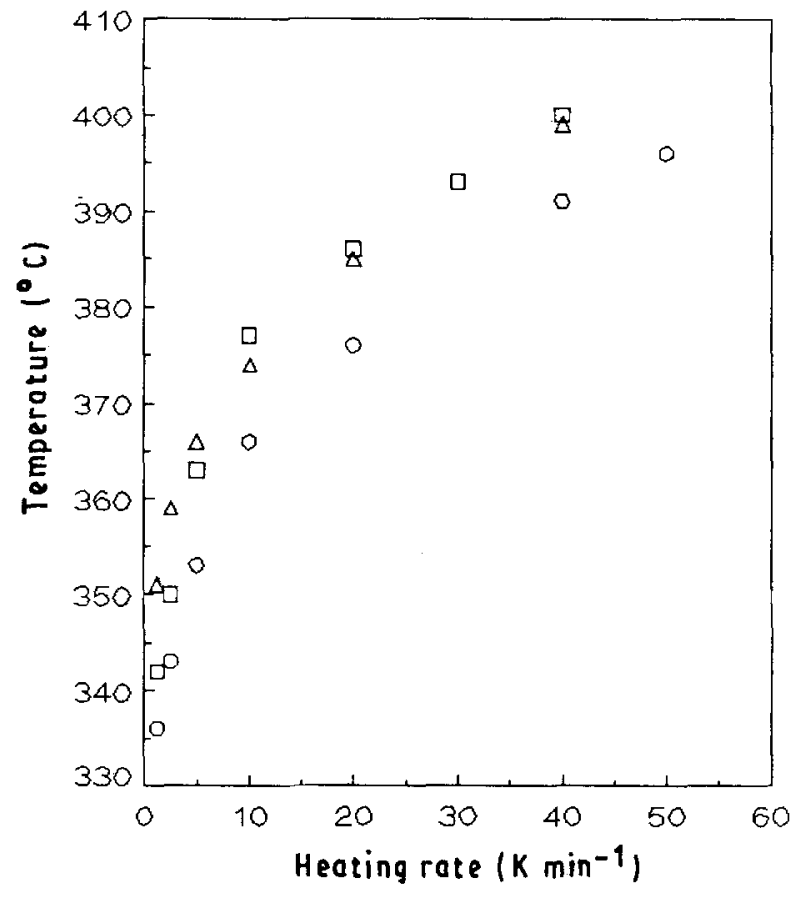

Figure 2 Temperatures, $T_{\mathrm{p}}$, at the maximum of the DSC peak as a function of heating rate, for two different particle sizes, compared with calculated $T_{\mathrm{p}}$ values (see also Section 4.3 ). $d:$ (O) $0.21 \mathrm{~mm}$, ( $\square$ ) $0.82 \mathrm{~mm},(\triangle)$ calculated.

increase in the heating rate results in a shift of the crystallization peak towards higher temperatures. Increasing the particle size has the same result.

\subsection{Growth rate}

The crystals that were found with XRD at temperatures up to at least $350^{\circ} \mathrm{C}$ were mainly $\beta-\mathrm{BaZrF}_{6}(\mathrm{~d})$ with some $\mathrm{NaZrF}_{5}$. These phases were also reported by Parker et al. [13]. The amount of $\mathrm{NaZrF}_{5}$ was relatively small and has therefore been neglected in the calculations. The crystals in the bulk and the crystals in the surface layer gave the same XRD pattern.

Fig. 3 shows crystal layer thickness versus heating time curves for glasses heat treated at $320^{\circ} \mathrm{C}$. Three samples were heated in air and three other samples of the same glass rod were heated in a dry nitrogen atmosphere (containing 8 p.p.m. $\mathrm{H}_{2} \mathrm{O}$ ). The results show clearly that heating in dry nitrogen results in longer times needed to form a layer of equal thickness in a glass compared to a glass heated in air. However, the growth rate remains constant within experimental error. These results indicate that surface crystallization is of importance. As discussed by Leede [12], surface crystallization is enhanced by the presence of water in the surrounding atmosphere, which leads to the formation of $\mathrm{ZrO}_{2}$ crystals on the surface at higher temperatures.

The evolution of the crystal layer with time was measured for a number of other temperatures from $310-374^{\circ} \mathrm{C}$. It was not possible to measure growth rate at higher temperatures because growth became too fast. Also, we already had to use three different rods, which makes comparisons less accurate. Nevertheless, crystal growth rates were determined from the 


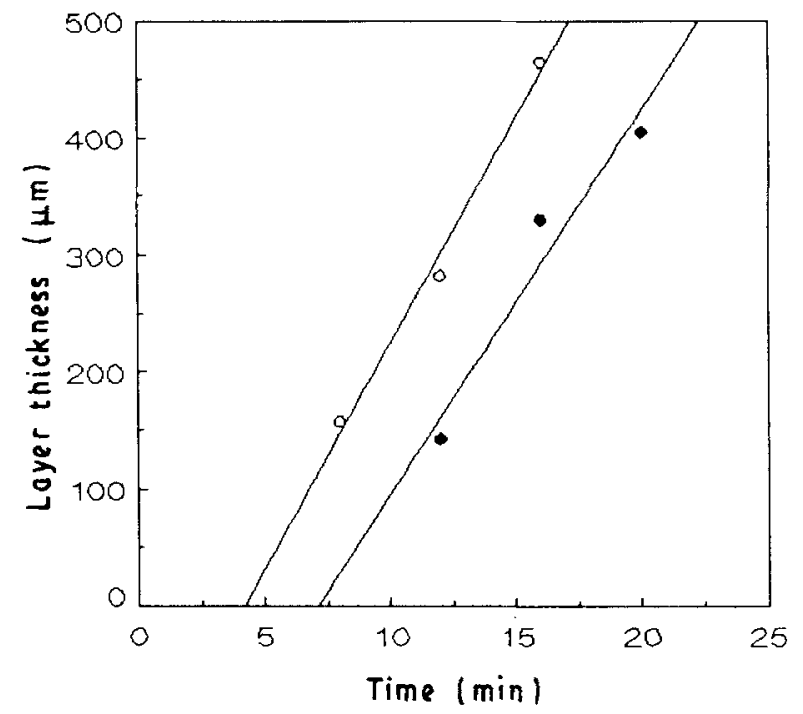

Figure 3 Crystal layer thickness as a function of time for etched glasses in (O) air and $(\diamond)$ a dry atmosphere (8 p.p.m.), at $T=320^{\circ} \mathrm{C}$.

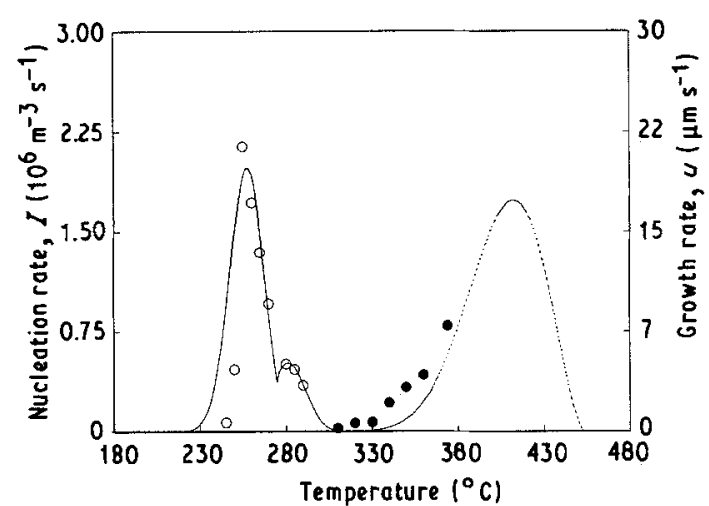

Figure $4(-)$ Theoretical, and experimental (O) nucleation and (C) growth rate curves.

layer thickness versus time curves for all temperatures listed above. The results are shown in Fig. 4; in this figure the theoretical crystal growth rate is also shown. The theoretical growth rate was calculated from Equation 6, using Equations 10 and 11 to calculate free-energy differences. Thus, it was assumed that the crystallization was not critically influenced by a (timedependent) diffusion mechanism. This assumption is made plausible in the Appendix, although it cannot be verified thoroughly due to lack of data.

A number of parameters characteristic of the fluoride glass of this study, had to be used for the calculation of the theoretical growth rate curve. The values for $\eta, T_{\mathrm{m}}, T_{\mathrm{l}}, \Delta H_{\mathrm{f}}$ and $V_{\mathrm{m}}$ were taken from the literature [14-18].

Also shown in Fig. 4 are the results of the experimental and theoretical evaluations of the nucleation rate. The values for $\sigma$ and $K$, necessary for the calculation of the theoretical nucleation curve were calculated by plotting $\ln (\mathrm{I \eta} / T)$ versus $1 /\left(\Delta G^{2} T\right)$ [3], which should yield a straight line according to Equation 1. In this way, the theoretical curve is partially based on experimental results as well. Nevertheless, the "theoretical" nucleation curve is useful, because it gives the possibility to extrapolate nucleation data to temper- ature ranges which could not be covered by measurement.

\subsection{Computer simulations}

From the evolution of the degree of crystallinity, $x$, with time, $t$, one can calculate its derivative $d x / d t$ which corresponds to the amount of material crystallizing per unit of time. The amount of heat evolving during crystallization of the glass in the DSC will be directly proportional to $d x / d t$. In other words, the DSC output is proportional to $d x / d t$ which can be obtained from the computer simulations.

For simplicity, it is assumed that the crystals are spherical, which is not true for the $\mathrm{BaZrF}_{6}$ crystals found in this study. Nevertheless, it is believed that the calculations give a usable description of the crystallinity of the glasses.

The temperature histories of the glass samples which need to be known for computer simulations were described before (see Sections 3.1 and 3.2). The cooling from the melt necessary to produce glass samples for DSC measurements, was approximated for the computer simulations by the parabola that fits between the liquidus temperature at $t=0$ and $240^{\circ} \mathrm{C}$ at $t=4 \mathrm{~min}$. Neither cooling from $240^{\circ} \mathrm{C}$ to room temperature nor reheating in the DSC to the start temperature $\left(200^{\circ} \mathrm{C}\right)$ influences crystallization.

The results of the computer simulations of the DSC measurements are also displayed in Fig. 2. The calculated peak temperatures, $T_{\mathrm{p}}$, are given as a function of heating rate. The results of the calculations are compared with the results obtained from the actual DSC measurements, for the particle sizes 0.21 and $0.82 \mathrm{~mm}$.

\subsection{Estimation of crystal scattering losses}

Because the nucleation rate and the growth rate are both known as functions of temperature, it is possible to calculate the degree of crystallinity in a fibre due to a certain heat treatment. The fitted nucleation rate curve and the theoretical growth curve were used for the calculations. Following the method described above, a crystal size distribution is obtained from which it is possible to estimate the scattering loss.

The theory of light scattering by small particles is treated by van de Hulst [19]. This theory has been applied for the evaluation of scattering loss, due to $\mathrm{ZrF}_{4}$ and $\mathrm{ZrO}_{2}$ crystallites in fluoride fibres by Hattori et al. [20]. These authors have studied the wavelength dependence of the scattering losses, but they have not quantified the losses which result from thermal treatments. The method used by these authors will be followed; details of the calculation will not be given here (see Reference 12). It is assumed that the scattered light rays do not interfere with each other, i.e. the number of crystallites per unit volume is assumed to be low. The refractive indexes of both the scattering crystals and the glass medium need to be known for the calculation; the refractive index of the $\mathrm{BaZrF}_{6}$ crystals is approximated by 1.59 (the refractive index of $\mathrm{ZrF}_{4}$ ), and the refractive index of the fluoride glass is taken as 1.5 , which gives a relative 
refractive index of 1.05. It is assumed that all power is transported through the core glass. It was also assumed that the heat treatment of the core glass is uniform. A more accurate calculation would be possible if one includes the possibility of a local time-temperature history in the fibre. The simplified time-temperature history of the preform and the resulting fibre is given schematically in Fig. 5. We have calculated the optical losses due to crystallization at $2.5 \mu \mathrm{m}$, the wavelength where one expects minimum intrinsic losses for these fluoride glasses. Two drawing temperatures were used for the calculations. The results are summarized in Table I. From these results it may be concluded that very rigorous temperature control is required during fibre drawing, in order to obtain ultra-low loss fibres.

\section{Discussion}

The results of the DSC measurements in Fig. 2 clearly show that surface nucleation and growth can play an important role in the crystallization of ZBLAN fluoride glasses, because smaller particles give lower $T_{\mathrm{p}}$ values. The importance of surface crystallization is also stressed when looking at Fig. 2. There is excellent agreement between the calculated and measured $T_{\mathrm{p}}$ values at heating rates exceeding $5 \mathrm{~K} \mathrm{~min}^{-1}$, for large particles. In contrast, small particles have significantly lower $T_{\mathrm{p}}$ values due to the contribution of surface nucleation to the crystallization of the particles. It has been shown [12] that it is possible to make an independent model for this surface crystallization that can be included in the theoretical simulations of the DSC measurements. It then becomes possible to calculate DSC curves taking surface crystallization into account, and the calculated results for small particles were found to agree well with the experimental results. The small discrepancy for lower heating rates in Fig. 2 may stem from underestimation of the growth rate at

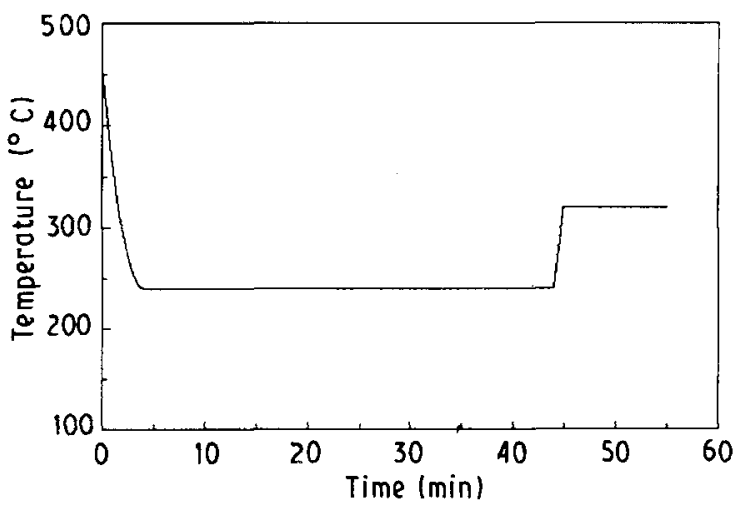

Figure 5 Temperature-time diagram for fibre drawing.

TABLE I Calculated scattering losses for two drawing temperatures

\begin{tabular}{llc}
\hline $\begin{array}{l}\text { Drawing temperature } \\
\left({ }^{\circ} \mathrm{C}\right)\end{array}$ & $\begin{array}{l}\text { Scattering loss } \\
\left(\mathrm{dB} \mathrm{km}{ }^{-1}\right)\end{array}$ & $\begin{array}{l}\text { Crystal size } \\
(\mu \mathrm{m})\end{array}$ \\
\hline 310 & 0.014 & 1 \\
320 & 25 & 10 \\
\hline
\end{tabular}

low temperatures. The samples will be heated for relatively longer periods at low temperatures when heated slowly. As can be seen from Fig. 4, the theoretical growth rate is about two orders of magnitude lower than the measured value in this range of low temperatures. This discrepancy is considerably smaller at higher temperatures.

It has already been mentioned that the growth rate experiments were not reproducible for the subsequent glasses that were produced. This may stem from a dependence of the growth rates on the oxygen content of the glasses [12], which is hard to control. Other uncertainties concerning the theoretical calculations are discussed in the Appendix: there is lack of data on liquidus temperatures and activity coefficients of the melt. For these reasons it does not seem useful to discuss further the observed differences between theory and experiment. Instead it would be better to test the outlined theory for a more simple multicomponent system, which crystallizes incongruently and for which more data are available.

It is obvious from the above discussion that the calculated fibre losses can only be taken as an estimate. The crystal growth rate that had been used for the calculations, was the theoretically evaluated growth rate, which was lower than the measured rates. However, crystallization of a fluoride glass may be very sensitive to oxygen content, and the preparation method of the glass for this study was not one giving the lowest possible oxygen level.

The estimated scattering losses for the fibre can be orders of magnitude higher than the intrinsic minimum losses predicted for the fluoride glass, of order $0.01-0.001 \mathrm{~dB} \mathrm{~km}^{-1}$. The calculated losses depend critically on the time-temperature history of the fibre. Further study of the exact time-temperature history is desired, to obtain an answer to the question whether losses of $0.01 \mathrm{~dB} \mathrm{~km}^{-1}$ can be attained, taking only crystallization into account for the determination of optical losses. The most critical thermal treatments are the annealing treatment of the preform, which largely determines the number of nuclei, and the actual fibre drawing during which the crystallites may grow at relatively large growth rates. A more accurate estimate would be possible by taking the vertical temperature profile in the preform during fibre drawing into account. As can be seen from Fig. 5, it was assumed for the calculations presented here that the glass is heated for $10 \mathrm{~min}$ to the fibre drawing temperature. In reality, the temperature will vary with the position in the neckdown region.

\section{Appendix}

The influence of diffusion on the growth rate of $\mathrm{BaZrF}_{6}$ crystals in a ZBLAN melt will be studied here. For growth to take place, $\mathrm{Na}^{+}$ions must diffuse from the crystal boundary to the melt, whereas $\mathrm{Ba}^{2+}$ ions must diffuse in the opposite direction. The volume concentration of $\mathrm{Zr}^{4+}$ ions is almost equal in crystal and melt.

The crystal growth kinetics for this case are described by Equations $6-11$. Knowledge of $\Delta G_{\mathrm{r}}$ (and 
thus the liquidus temperature) and the diffusion coefficient, $D$, is necessary to obtain a solution of this set of equations. The free-energy difference, $\Delta G_{\mathrm{r}}$, between the liquid at the interface (composition $x_{r}^{\mathbf{A}}$ ) and the pure liquid $\mathrm{A}$, depends on the concentration of $\mathrm{A}$ at the interface. The liquidus temperature used in Equation 10 will also vary with $x_{\mathrm{r}}^{\mathrm{A}}$. Unfortunately, there are no experimental data available for the variation of $T_{1}$ with composition. For the calculations presented below, a rough estimate was used: 1 mol fluoride glass consists of $0.2 \mathrm{~mol} \mathrm{ZrF}_{4} \mathrm{BaF}_{2}$ and $0.6 \mathrm{~mol}$ of the remaining components, giving $\left(\mathrm{ZrF}_{4}\right)_{33}(\mathrm{NaF})_{20}$ $\left(\mathrm{LaF}_{3}\right)_{4}\left(\mathrm{AlF}_{3}\right)_{3}$. Therefore, the molar fraction of the crystallizing phase, $x^{\mathrm{A}}$, is 0.25 . This composition can be located in a phase diagram with $\mathrm{ZrF}_{4} \mathrm{BaF}_{2}$ on one end, and $\left(\mathrm{Z}_{\mathrm{r}} \mathrm{F}_{4}\right)_{33}(\mathrm{NaF})_{20}\left(\mathrm{LaF}_{3}\right)_{4}\left(\mathrm{AlF}_{3}\right)_{3}$, on the other end, with $x^{A}$ at the horizontal axis. For the calculations we need to know the variation of the liquidus temperature with $x^{\mathrm{A}}$. Only a very limited amount of data is available from the literature:

At $x^{\mathrm{A}}=0, T_{\mathrm{m}}=620^{\circ} \mathrm{C}$ (this temperature was estimated by taking the liquidus of the $\left(\mathrm{ZrF}_{4}\right)_{33}(\mathrm{NaF})_{20}$ system, which is obtained from a phase diagram of the $\mathrm{ZrF}_{4}-\mathrm{NaF}$ system [21]);

At $x^{\mathrm{A}}=0.25, T_{1}=454^{\circ} \mathrm{C}$ (this is the melting temperature of the glass of this study [13]);

At $x^{\mathrm{A}}=1, T_{\mathrm{m}}=750^{\circ} \mathrm{C}[15]$.

A simplified liquidus curve can be obtained from linear interpolations between those respective values for the melting temperature.

The interdiffusion coefficient, $D$, must be known for the solution of this set of equations. Only one reference has been found where interdiffusion coefficients for diffusion in fluoride glasses have been reported [22]. The base glass composition was the same as the ZBLAN glass of this study. An Arrhenius plot of the sodium/lithium interdiffusion coefficient versus temperature has indicated an activation energy of $\approx 310 \mathrm{~kJ} \mathrm{~mol}^{-1}$, from measurements over the temperature range $256-280^{\circ} \mathrm{C}$. The interdiffusion coefficients ranged from $\approx 6 \times 10^{-16}-2 \times 10^{-14} \mathrm{~m}^{2} \mathrm{~s}^{-1}$ over this temperature range. Sodium/lead interdiffusion coefficients were found to be at least one order of magnitude smaller over the same temperature range. It is assumed here that the coefficient for sodium/barium interdiffusion is of the same order of magnitude as for sodium/lead interdiffusion. Furthermore, it is also assumed that the interdiffusion coefficient can be described by an Arrhenius equation over a wide range of temperatures, extending from $T_{\mathrm{g}}$ to $350^{\circ} \mathrm{C}$ or more. The thickness of the diffusion layer, $\delta$, can then be estimated from Equation 9 for several instants of time. The radius of the (spherical) crystal was taken as $0.5 \mu \mathrm{m}$, and it was found that $\delta$ becomes nearly constant after a relatively short time interval.

It is possible now to calculate the growth rate, $u$, at a given temperature, because the concentration of $A$ at the interface $c_{\mathrm{r}}^{\mathrm{A}}$, the flux $j$ of $\mathrm{A}$ to the interface and the growth rate $u$ can be solved from Equations 6-8. $c_{\mathrm{r}}^{\mathrm{A}}$ and $j$ were eliminated and an expression of the type $u$ $=f(u)$ was obtained from which it was possible to determine $u$ numerically. The growth rates which were calculated in this way were at most $10 \%$ higher than the growth rates which can be calculated if it is assumed that the concentration at the interface equals the bulk liquid concentration (when the process is not diffusion limited at all). The fact that the growth rates come out higher when diffusion is taken into account is rather surprising. It stems from the dependence of $\Delta G_{\mathrm{r}}$ on $x_{\mathrm{r}}^{\mathrm{A}}$ (see Equation 10). Because $\Delta G=\Delta G_{\mathrm{r}}$ $+\delta G_{\mathrm{r}}$ and $\Delta G$ is a constant, we can also consider the variation of the driving force $\delta G_{\mathrm{r}}$ with composition. From Equation 3 it follows that the driving force for crystallization may increase for a decreasing concentration. Unfortunately, there are no data available on the activity coefficients of the melt, and therefore it cannot be verified if Equations 10 and 3 are correct for the system of this study. There is also uncertainty about the variation of the liquidus temperature $T_{1}$ with composition.

The preliminary results presented suggest that it is not necessary to take diffusion into account for a reasonable estimation of the growth rate.

\section{References}

1. D. R. UHLMANN, in "Advances in Ceramics", Vol. 4, edited by J. H. Simmons, D. R. Uhlmann and G. H. Beall (1981) p. 80.

2. P. F. JAMES, ibid, p. 1.

3. G. de LEEDE, H. de WAAL and F. HAKKENS, J. Amer. Ceram. Soc. 72 (1989) C-1991.

4. P. W. FRANCE, S. F. CARTER, M. W. MOORE and J.R WILLIAMS, in "Halide Glasses for Infrared Fiberoptics", edited by R. M. Almeida, NATO ASI series. Series E, Applied Sciences, No. 123 (1986) p. 253.

5. M. REY, Discuss. Faraday Soc. 4 (1948) 259.

6. HILDEBRAND, in "Solubility of Non-Electrolytes", 2nd Edn (1936) Ch. 4

7. M. C. WEINBERG, P. I. K. ONORATO and D. R. UHLMANN, J. Amer. Ceram. Soc. 63 (1980) 175.

8. Z. STRNAD and R. W. DOUGLAS, Phys. Chem. Glasses $\mathbf{1 4}$ (1973) 33.

9. E. D. ZANOTTO and P. F. JAMES, J. Non-Cryst. Solids 74 (1985) 373.

10. H. YINNON and D. R. UHLMANN, ibid. 54 (1983) 253.

11. H. W. SCHNEIDER, A. SCHOBERTH, A. STAUDT and Ch. GERNDT, Siemens Forsch. Entwickl. Ber. Bd. 17 (1988) 147.

12. G. L. A. de LEEDE, PhD thesis, Eindhoven University of Technology (1989) Ch. 5, 6.

13. J. M. PARKER, A. B. SEDDON and A. G. CLARE, Phys. Chem. Glasses 28 (1987) 4.

14. S. N. CRICHTON, R. MOSSADEGH, C. T. MOYNIHAN, P. K. GUPTA and M. G. DREXHAGE, Mater. Sci. Forum $19-20$ (1987) 435.

15. J. P. LAVAL, D. MERCURIO-LAVAUD and B. GAUDREAU, Rev. Chim. Miner. 11 (1974) 742.

16. L. E. BUSSE, G. LU, D. C. TRAN and G. H. SIGEL, Mater. Sci. Forum 5 (1985) 219.

17. P. K. GUPTA, J. Amer. Ceram. Soc. 71 (1988) C-345.

18. B. MEHLHORN and R. HOPPE, Z. Anorg. Allgem. Chem. 425 (1976) 180 .

19. H. C. v.d. HULST, "Light scattering by small particles" (Wiley, New York, 1957) pp. 85-91.

20. H. HATTORI, S. SAKAGUCHI, T. KANAMORI and Y. TERUNUMA, Appl. Opt. 26 (1987) 2683.

21. C. J. BARTON, W. R. GRIMES, H. INSLEY, R. E. MOORE and R. E. THOMAS, J. Phys. Chem. 62 (1958) 665.

22. E. A. MARSH, B. CANTOR, S. J. WILSON and M. G SCOTT, Adv. Ceram. Mater. 3 (1988) 207

Received 26 March 1990

and accepted 14 June 1991 